The Egyptian Journal of Hospital Medicine (April 2019) Vol. 75 (5), Page 2825-2832

\title{
Combined Low Dose Aspirin and Steroids vs Aspirin Only in Management of Unexplained Recurrent Miscarriage
}

Fahd A. El Omda, Ahmed T. Abd ElFattah, Ahmed M. Ragab*

Department of Gynecology and Obstetrics, Faculty of Medicine, Al-Azhar University

*Corresponding author: Ahmed M. Ragab; Mobile: 01093784852; Email: manareisa89@gmail.com

\begin{abstract}
Background: recurrent pregnancy loss (RPL) is defined as at least two or three sequential abortions before the 20 th week of gestation. RPL occurs in $1 \%$ to $5 \%$ of all pregnancies.

Aim of the Work: to assess the efficacy of low dose aspirin and steroids therapy versus Aspirin Study in the management of women with recurrent miscarriage.

Patients and Methods: this randomized clinical trial was conducted in the repeated miscarriage clinics in the Obstetrics and Gynecology Department, in Al-Azhar University Hospital on 100 pregnant women, who fulfilled the inclusion criteria and after taking an informed consent. Group 1: included 50 pregnant females administered with low dose aspirin $75 \mathrm{mg}$ tablet (one tablet twice daily) and prednisolone $5 \mathrm{mg}$ two tablets twice daily (20mg). Group 2: included 50 pregnant females administered with low dose aspirin $75 \mathrm{mg}$ tablet (one tablet twice daily). Both groups were followed in Elhussein hospital recurrent miscarriage clinic every two weeks by ultrasonography from the incidence of the pregnancy till delivery.

Results: women treated with prednisolone (PSL) plus LDA had a $32.2 \%$ higher live birth rate than group II and according to on-going pregnancy data was in group I 37/50(74\%) and in group II 21/50(42\%) OR (C.I. 95\% 4.128 [2.142-7.952] RR (C.I. 95\% 1.875 [1.401-2.505] p<0.001, with a significant difference between the two groups. There was a significant difference between the two groups as regards the development of bruising $(\mathrm{P}<0.05)$. Conclusion: combination treatment consisting of prednislone and low dose aspirin might be an effective treatment for women with idiopathic pregnancy loss.
\end{abstract}

Keywords: Aspirin, Steroids, Unexplained Recurrent Miscarriage.

\section{INTRODUCTION}

Recurrent pregnancy loss (RPL) is defined as two or three consecutive miscarriages at least before the 20th week of pregnancy. RPL occurs in $1 \%$ to $5 \%$ of all pregnancies. Although many factors, such as environmental factors, stress factors, chromosomal abnormalities, defects of coagulation protein, anatomic endocrine disorders and the autonomic immune system are involved in about $60 \%$ of RPLs, in the remaining $40 \%$ of cases, the causes of miscarriage are unknown and classified As a nonjustified RPL (URPL) ${ }^{(1)}$.

Fifty percent of the RPL is caused by anatomical factors, immunology, genetics, endocrinology, coagulation, and environmental. However, in $50 \%$ of cases, the cause of abortion is unknown or idiopathic $^{(2)}$. RPL is a major health problem, affecting $5 \%$ of females of childbearing age. Women of childbearing age face significant economic, emotional and social problems due to RPL ${ }^{(3)}$. Established and suggested risk factors for recurrent miscarriage are increasing number of successive previous pregnancy losses ${ }^{(4)}$, parental chromosomal anomalies, maternal thrombophilia disorders, and structural uterine anomalies. Finally, increasing maternal age is accepted as the most important risk factor for future miscarriage both in women with recurrent miscarriages and in the general population ${ }^{(5)}$.

The proposed and proposed risk factors for recurrent miscarriages are an increase in the number of previous consecutive pregnancies, 4 cases of parental chromosomal abnormalities, maternal thrombosis disorders, and structural defects in the uterus. Finally, the increase in the age of the mother is accepted as the most important risk factor for future abortion in women with recurrent miscarriages and in the general population.

About $50 \%$ of recurrent pregnancy loss cases still remain unexplained, or idiopathic. In this group of patients, fetal chromosomal abnormalities have been reported to be the most common cause of recurrent pregnancy loss, accounting for up to $55 \%$ of cases, thus leaving a remainder of $24.5 \%$ of truly unexplained recurrent pregnancy loss ${ }^{(\boldsymbol{6})}$.

Although progesterone appears to be the main factor initiating decidualization, a number of other factors including cytokines appear to facilitate this event. Failure in either the early blastocyst endometrial dialogue or decidualization may lead to implantation or pregnancy failure, alteration in the expression of a number of factors thought to contribute to the embryo/ endometrial dialogue have been shown at this time in endometrium from women with recurrent miscarriage ${ }^{(7)}$.

The concentrations of different endometrial leukocytes have therefore been investigated in a number of studies to find links to the development of miscarriages ${ }^{(8)}$. We performed this study on women who presented with unexplained recurrent to explore 
the efficacy of low dose aspirin and steroids in the management of such cases.

\section{AIM OF THE WORK}

The aim of this study is to assess the efficacy of low dose aspirin and steroids therapy vs Aspirin Study in the management of women with recurrent miscarriage.

\section{PATIENTS AND METHODS}

This randomized clinical trial was conducted in the repeated miscarriage clinics in the Obstetrics and Gynecology Department, in Elsayed Galal and Elhussein hospitals. Al-Azhar University; Cairo, Egypt from November 2017 till December 2018.

The study was approved by the Ethics Board of Al-Azhar University.

\section{Study groups:}

- Group 1: This group included 50 pregnant females who administered low dose aspirin $75 \mathrm{mg}$ tab. (One tablet twice daily) and prednisolone $5 \mathrm{mg}$ two tablets twice daily $(20 \mathrm{mg})$. The intervention started from the start of the pregnancy till 14 weeks gestation. Low dose aspirin only was continued till 36 week.

- Group 2: This group included 50 pregnant females who were administered with low dose aspirin $75 \mathrm{mg}$ tab., one tablet twice daily. The intervention started from the start of the pregnancy.

Both groups were followed in Elhussein hospital recurrent miscarriage clinic every two weeks by ultrasonography from the incidence of the pregnancy till delivery.

\section{Inclusion criteria:}

The study included patients with a history of two or more consecutive miscarriages, with ages from 18 years till 35 years with viable current early pregnancy ( $<8$ weeks gestation) and a history of unexplained recurrent miscarriage (which was defined as $\geq 2$ previous miscarriages at $<20$ weeks, gestation).

\section{Exclusion criteria:}

A) Parental chromosomal abnormalities, Anatomical abnormality as uterine anomalies, e.g. uterine septum incompetent internal cervical os, Maternal endocrinological defects e.g. a luteal-phase defect (as determined by a timed endometrial biopsy), which are all known causes of recurrent fetal loss, PCOD (poly cystic ovarian disease), thyroid disease, hyperprolactinemia, Maternal thrombophilia, e.g. Factor V Leidin deficiency protein C deficiency protein $\mathrm{S}$ deficiency, antithrombin III deficiency, Maternal anti phospholipid anti body syndrome. Systemic lupus erythematosus that fulfilled four or more of the criteria of the American College of Rheumatology ${ }^{(9)}$ and Diagnosis of pregnancy after 8 weeks gestation.
B) Contraindications of aspirin: confirmed peptic ulcer disease within the past three years and sensitivity to aspirin.

\section{C) Contraindications of steroids:}

Diabetes mellitus, previous gestational diabetes mellitus, diastolic blood pressure greater than 90 $\mathrm{mm} \mathrm{Hg}$ and previously untreated tuberculosis

D) Randomization: was done by using dark, sealed envelopes detailing the intervention, which was selected from a table of numbers either 1 or 2 (1 means the group took low dose aspirin and steroids and 2 means the group took aspirin only); Created by computer generated randomization table program.

\section{E) Allocation:}

For each patient, an envelope was selected from the sequentially numbered envelopes on the day of recruitment by a nurse not involved in the study.

\section{Consent:}

Informed consents from all participating patients in the study were taken.

\section{History:}

A complete history was obtained.

\section{Examination:}

- General examination was done for PCOD, thyroid disease galactorrhea, hirsutism, evidence of autoimmune disorder.

- Abdominal examination was done.

\section{Investigation:}

Obstetric ultrasonography were conducted to assess the viability of pregnancy and gestational age for all participants and to assess: No. of fetaie, ectopic, fetal viability, congenital fetal malformation, lie, presentation, IUGR, MBPP, and Doppler (if needed). Amniotic fluid amount and turbidity Placental site, grading, morbid adherence, thickness hemorrhage Associated pelvic mass with pregnancy e.g. ovarian cyst, uterine malformations, cervical length, inner to inner diameters Routine laboratory investigations: $\mathrm{CBC}$, urine analysis, random blood sugar, liver and kidney function tests.

Screening for anticardiolipin antibodies, lupus anticoagulant or anti-b2-glycoprotein I antibodies if not previously done. Endocrine screening: prolactin, $\mathrm{TSH}$, and $\mathrm{HbAlc}$ if not previously done.

\section{Statistical analysis}

Data were analyzed using Statistical Program for Social Science (SPSS) version 20.0. Quantitative data were expressed as mean \pm standard deviation (SD). Qualitative data were expressed as frequency and percentage. 


\section{The following tests were done:}

- Independent-samples t-test of significance was used when comparing between two means.

- Mann Whitney U test: for two-group comparisons in non-parametric data.

- Chi-square $\left(\mathrm{X}^{2}\right)$ test of significance was used in order to compare proportions between two qualitative parameters.

- Odds ratio: An odds ratio (OR) is a measure of association between an exposure and an outcome. The OR represents the odds that an outcome will occur given a particular exposure, compared to the odds of the outcome occurring in the absence of that exposure.

- Relative risk (risk ratio): The ratio between the risk of the outcome in the first group to the risk of outcome in the second group.

- NNT: Number needed to treat is the number of patients you need to treat to prevent one additional ad outcome.

- Probability (P-value):

- P-value $<0.05$ was considered significant.

- P-value <0.001 was considered as highly significant.

- P-value >0.05 was considered insignificant.

\section{RESULTS}

Table (1): Comparison between Group I and group II according age and BMI

\begin{tabular}{|c|c|c|c|c|}
\hline & $\begin{array}{c}\text { Group I } \\
(n=50)\end{array}$ & $\begin{array}{c}\text { Group II } \\
(\mathbf{n}=\mathbf{5 0})\end{array}$ & t-test & p-value \\
\hline $\begin{array}{l}\text { Age (years) } \\
\text { Mean } \pm S D \\
\text { Range }\end{array}$ & $\begin{array}{c}28.70 \pm 4.12 \\
19-35\end{array}$ & $\begin{array}{c}29.58 \pm 4.52 \\
19-35\end{array}$ & 1.034 & 0.312 \\
\hline $\begin{array}{l}\text { BMI [wt(ht })^{2} \text { ] } \\
\text { Mean } \pm \text { SD } \\
\text { Range }\end{array}$ & $\begin{array}{c}29.50 \pm 3.15 \\
24-39 \\
\end{array}$ & $\begin{array}{c}30.08 \pm 3.46 \\
23-40\end{array}$ & 0.769 & 0.383 \\
\hline
\end{tabular}

This table shows no statistically significant difference between groups according age and BMI.

Table (2): Comparison between Group I and group II according parity

\begin{tabular}{|l|c|c|c|c|}
\hline Parity & $\begin{array}{c}\text { Group I } \\
(\mathbf{n = 5 0})\end{array}$ & $\begin{array}{c}\text { Group II } \\
(\mathbf{n = 5 0})\end{array}$ & x2 & p-value \\
\cline { 1 - 3 } Primigravida & $41(82 \%)$ & $38(76 \%)$ & \multirow{2}{*}{0.542} & \multirow{2}{*}{0.461} \\
\hline Multipara & $9(18 \%)$ & $12(24 \%)$ & & \\
\hline Total & $50(100 \%)$ & $50(100 \%)$ & & \\
\cline { 1 - 3 }
\end{tabular}

This table shows no statistically significant difference between groups according parity.

Table (3): Comparison between Group I and group II according no. of previous live birth

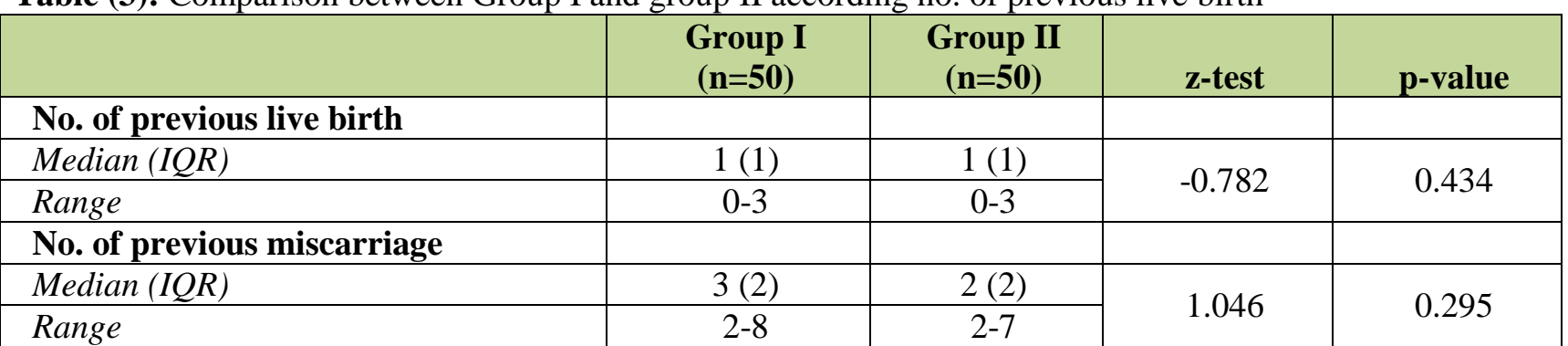

This table shows no statistically significant difference between groups according no. of previous live birth and no. of previous misscarrige.

Table (4): Comparison between Group I and group II according miscarriage

\begin{tabular}{|c|c|c|c|c|c|c|}
\hline Miscarriage & $\begin{array}{c}\text { Group I } \\
(\mathbf{n}=50)\end{array}$ & $\begin{array}{c}\text { Group II } \\
(\mathbf{n}=\mathbf{5 0})\end{array}$ & $\begin{array}{c}\text { OR (C.I. } \\
95 \%\end{array}$ & $\begin{array}{c}\text { RR } \\
\text { (C.I. } \\
\text { 95\% }\end{array}$ & $\mathrm{x} 2$ & p-value \\
\hline Yes & $13(26 \%)$ & $29(58 \%)$ & \multirow{3}{*}{$\begin{array}{c}0.267 \\
{[0.139-} \\
0.515]\end{array}$} & \multirow{3}{*}{$\begin{array}{l}0.478 \\
{[0.320-} \\
0.712]\end{array}$} & \multirow{3}{*}{10.509} & \multirow{3}{*}{$\begin{array}{c}<0.001 \\
(\mathrm{HS})\end{array}$} \\
\hline No & $37(74 \%)$ & $21(42 \%)$ & & & & \\
\hline Total & $50(100 \%)$ & $50(100 \%)$ & & & & \\
\hline
\end{tabular}

This table shows highly statistically significant difference between groups according miscarriage. 
Table (5): Comparison between Group I and group II according gestational age at miscarriage

\begin{tabular}{|l|c|c|c|c|}
\hline $\begin{array}{c}\text { Gestational Age at } \\
\text { miscarriage }\end{array}$ & $\begin{array}{c}\text { Group I } \\
(\mathbf{n = 1 3})\end{array}$ & $\begin{array}{c}\text { Group II } \\
(\mathbf{n = 2 9})\end{array}$ & t-test & p-value \\
\cline { 1 - 3 } Mean \pm SD & $9.77 \pm 1.24$ & $9.69 \pm 1.07$ & 0.045 & 0.833 (NS) \\
\hline Range & $8-12$ & $8-13$ & 0.045 \\
\hline
\end{tabular}

This table shows no statistically significant difference between groups according gestational age at miscarriage.

Table (6): Comparison between Group I and group II according ongoing pregnancy

\begin{tabular}{|c|c|c|c|c|c|c|c|}
\hline $\begin{array}{c}\text { On going } \\
\text { pregnancy }\end{array}$ & $\underset{(\mathbf{n}=50)}{\text { Group I }}$ & $\begin{array}{c}\text { Group II } \\
(\mathbf{n}=\mathbf{5 0})\end{array}$ & $\begin{array}{c}\text { OR (C.I. } \\
\text { 95\% }\end{array}$ & $\begin{array}{l}\text { RR } \\
\text { (C.I. } \\
\text { 95\% }\end{array}$ & $\begin{array}{c}\text { Effe } \\
\text { ct } \\
\text { size }\end{array}$ & $\mathbf{x} 2$ & p-value \\
\hline Yes & $37(74 \%)$ & $21(42 \%)$ & \multirow{3}{*}{$\begin{array}{c}4.128 \\
{[2.142-} \\
7.952]\end{array}$} & 1.875 & \multirow{3}{*}{$\begin{array}{c}32.2 \\
\%\end{array}$} & \multirow[b]{3}{*}{$\begin{array}{c}10.50 \\
9\end{array}$} & \multirow{3}{*}{$\begin{array}{c}<0.001 \\
(\mathbf{H S})\end{array}$} \\
\hline No & $13(26 \%)$ & $29(58 \%)$ & & {$[1.40$} & & & \\
\hline Total & $50(100 \%)$ & $50(100 \%)$ & & $\begin{array}{c}1- \\
2.505 \\
]\end{array}$ & & & \\
\hline
\end{tabular}

This table shows highly statistically significant difference between groups according on-going pregnancy.

Table (7): Comparison between Group I and group II according bleeding in early pregnancy

\begin{tabular}{|c|c|c|c|c|c|c|}
\hline $\begin{array}{l}\text { Bleeding in Early } \\
\text { Pregnancy }\end{array}$ & $\begin{array}{c}\text { Group I } \\
(\mathbf{n}=\mathbf{5 0})\end{array}$ & $\begin{array}{c}\text { Group II } \\
(\mathbf{n}=\mathbf{5 0})\end{array}$ & $\begin{array}{l}\text { OR (C.I. } \\
95 \%\end{array}$ & $\begin{array}{c}\text { RR } \\
\text { (C.I. } \\
\text { 95\% } \\
\end{array}$ & $\mathbf{x} 2$ & p-value \\
\hline Yes & $20(40 \%)$ & $25(50 \%)$ & \multirow{3}{*}{$\begin{array}{c}0.684 \\
{[0.366-} \\
1.274]\end{array}$} & 0.818 & \multirow[b]{3}{*}{1.010} & \multirow[b]{3}{*}{$0.315(\mathrm{NS})$} \\
\hline No & $30(60 \%)$ & $25(50 \%)$ & & {$[0.56$} & & \\
\hline Total & $50(100 \%)$ & $50(100 \%)$ & & $\begin{array}{c}7- \\
1.178 \\
]\end{array}$ & & \\
\hline
\end{tabular}

This table shows no statistically significant difference between groups according bleeding in early pregnancy.

Table (8): Comparison between Group I and group II according pregnancy complications

\begin{tabular}{|l|c|c|c|c|}
\hline Pregnancy Complications & $\begin{array}{c}\text { Group I } \\
(\mathbf{n = 5 0})\end{array}$ & $\begin{array}{c}\text { Group II } \\
(\mathbf{n = 5 0})\end{array}$ & $\mathbf{x 2}$ & p-value \\
\hline Pregnancy induced HTN & $3(6.0 \%)$ & $3(6.0 \%)$ & 0.105 & 0.702 \\
\hline Pre eclamptic toxemia & $3(6.0 \%)$ & $2(4.0 \%)$ & 0.002 & 0.924 \\
\hline Gestational DM & $1(2.0 \%)$ & $0(0.0 \%)$ & 0.001 & 0.942 \\
\hline Pre TermLabour PTL & $4(8.0 \%)$ & $1(2.0 \%)$ & 2.310 & 0.113 \\
\hline Intra Uterine Fetal Death & $2(4.0 \%)$ & $3(6.0 \%)$ & 0.138 & 0.668 \\
\hline Intra Uterine Growth retardation & $5(10.0 \%)$ & $3(6.0 \%)$ & 0.114 & 0.692 \\
\hline Thrombocytopenia & $2(4.0 \%)$ & $0(0.0 \%)$ & 2.243 & 0.118 \\
\hline Epistaxis & $5(10.0 \%)$ & $2(4.0 \%)$ & 1.823 & 0.158 \\
\hline Bleeding per gum & $6(12.0 \%)$ & $2(4.0 \%)$ & 3.434 & $0.045^{*}$ \\
\hline Heamatourea & $7(14.0 \%)$ & $3(6.0 \%)$ & 2.224 & 0.120 \\
\hline Brousing & $13(26.0 \%)$ & $0(0.0 \%)$ & 12.873 & $<0.001^{* *}$ \\
\hline DVT & $2(4.0 \%)$ & $1(2.0 \%)$ & 0.190 & 0.948 \\
\hline GIT problem & $8(16.0 \%)$ & $2(4.0 \%)$ & 2.593 & 0.093 \\
\hline Aprabtioplacente & $0(0.0 \%)$ & $1(2.0 \%)$ & 0.000 & 0.948 \\
\hline
\end{tabular}

This table shows statistically significant difference between groups according bleeding per gum and brousing.

Table (9): Kaplan-Meier curves between group I and group II regarding pregnancy until delivery

\begin{tabular}{|c|c|c|c|c|c|c|}
\hline \multirow{3}{*}{ Groups } & \multicolumn{4}{|c|}{ Median } & \multirow{2}{*}{\multicolumn{2}{|c|}{$\begin{array}{l}\text { og Rank (Mentel- } \\
\text { Cox) }\end{array}$}} \\
\hline & \multirow{2}{*}{ Estimate } & \multirow{2}{*}{ Std. Error } & \multicolumn{2}{|c|}{ 95\% Confidence Interval } & & \\
\hline & & & Lower Bound & Upper Bound & $\mathbf{x}^{2}$ & p-value \\
\hline Group I & 32.88 & 1.94 & 29.08 & 36.68 & & \\
\hline Group II & 22.84 & 2.19 & 18.55 & 27.13 & 10.385 & $0.001(\mathrm{HS})$ \\
\hline Overall & 27.86 & 1.55 & 24.83 & 30.89 & & \\
\hline
\end{tabular}




\section{DISCUSSION}

This study assessed the efficacy of low dose aspirin and steroids therapy in the management of women with idiopathic recurrent miscarriage.

The current study showed a statistically significant difference between two groups according on-going pregnancy as in group I $37 / 50(74 \%)$ and in group II 21/50 (42\%) OR (C.I. 95\% 4.128 [2.1427.952] RR (C.I. 95\%1.875 [1.401 - 2.505] p<0.001 (HS), the mean age in the group I was $(28.70 \pm 4.12)$ and they were in the age group of 19-35 years while the mean BMI was $(29.50 \pm 3.15)$. The mean age in the group II was (29.58 \pm 4.52$)$ and they were in the age group of 19-35 years while the mean BMI was $(30.08 \pm 3.46)$ with no statistically significant difference between the two groups $(\mathrm{P}>0.05)$ as regards the age and BMI. As regards other clinic-demographic data of the participants, there was no significant difference between the two groups as regards parity, number of previous live birth, number of previous miscarriages, the duration of previous pregnancies.

Based on current evidence, aspirin (less than $150 \mathrm{mg} / \mathrm{d}$ ) during the second and third trimesters appears to be safe, while the safety of higher doses of aspirin during the first trimester remains uncertain ${ }^{(\mathbf{1 0})}$.

Although a different design was used, in her study ${ }^{(11)}$ evaluated the effect of aspirin $(50 \mathrm{mg} /$ day $)$ on live birth rate in 66 pregnant women with preceding RM with or without detectable anticardiolipin antibodies and no other apparent risk factors for their previous miscarriages. RM was defined as three or more consecutive miscarriages (occurring before 22 weeks of gestational age). Aspirin was compared with placebo, and medication was started as soon as a home urinary pregnancy test became positive and continued until delivery. Pooled analysis from 256 patients showed that compared to placebo, aspirin did not increase live birth (risk ratio (RR) 0.94, 95\% confidence interval (CI) 0.80 to 1.11$)^{(11,12)}$.

Nine studies, including data of 1228 women, were included in the review evaluating the effect of either LMWH (enoxaparin or nadroparin in varying doses) or aspirin or a combination of both, on the chance of live birth in women with recurrent miscarriage, with or without inherited thrombophilia. Studies were heterogeneous with regard to study design and treatment regimen and three studies were considered to be at high risk of bias. Two of these three studies at high risk of bias showed a benefit of one treatment over the other, but in sensitivity analyses (in which studies at high risk of bias were excluded) anticoagulants did not have a beneficial effect on live birth, regardless of which anticoagulant was evaluated (risk ratio (RR) for live birth in women who received aspirin compared to placebo 0.94 , (95\% confidence interval (CI) 0.80 to $1.11, \mathrm{n}=256$ ), in women who received LMWH compared to aspirin RR 1.08 (95\%
CI 0.93 to $1.26, \mathrm{n}=239$ ), and in women who received LMWH and aspirin compared to Aspirin only RR 1.01 (95\% CI 0.87 to 1.16$) \mathrm{n}=322)^{(\mathbf{1 3})}$.

Also Zein et al. ${ }^{(13)}$ confirmed that, the use of aspirin plus heparin did not significantly increase the live birth rate in women with recurrent unexplained miscarriage.

That agreement with Kaandorp et al. (14) recorded that their findings do not support the hypothesis that either combination therapy with aspirin and nadroparin or aspirin alone improves the chance of a live birth for women with unexplained recurrent miscarriage.

In contrast to aspirin lack of efficacy among women with early unexplained recurrent miscarriage, low dose aspirin significantly increased the prospective live birth rate among women with a previous late miscarriage. This support the hypothesis that a number of cases of second trimester miscarriage and later pregnancy complications have a thrombotic aetiology ${ }^{(15)}$.

Some are reported the benefit effect of use low dose aspirin as a prophylaxis in treatment of unexplained recurrent miscarriage as Ahmed et al. (16) who reported that The use of prophylactic dose of calheparin and aspirin is associated with increased chance of passing 1st trimester safely regardless the age, body mass index or number of abortion in women with unexplained recurrent spontaneous abortion.

Also Rai, et al. ${ }^{(17)}$ reported that Treatment with aspirin and heparin leads to a significantly higher rate of live births in women with a history of recurrent miscarriage.

Also as regard to use of predinislone alone in treatment of recurrent miscarriage.

Recent study published by Tang et al. ${ }^{(18)}$ about the use of prednisolone in patients with high levels of uterine natural killer (uNK) cells, he conducted his study on 160 eligible women were screened with an endometrial biopsy and those with high uNK cell density were invited to return when pregnant for randomization to prednisolone (20 mg for 6 weeks, 10 $\mathrm{mg}$ for 1 week, $5 \mathrm{mg}$ for 1 week) or identical placebo tablets. Randomization was by random number generation and patients, clinicians and outcome assessors were blinded to allocation. Which resulted that, the live birth rate was $12 / 20(60 \%)$ in the prednisolone group and 8/20 (40\%) in the placebo group, and this was not significant (RR1.5, 95\% CI $0.8-2.9)$. There was only one pre-term delivery of 37 weeks in the prednisolone group, and all others delivered at term. The mean birth weight was similar in the two groups, with no pregnancy complications of IUGR or macrosomia.

There were also no reports of gestational hypertension, pre-eclampsia or gestational diabetes in either group. There were no adverse fetal outcomes. 
With the same to our regimen, in which $10 \mathrm{mg} / \mathrm{d}$ of prednisolone twice daily was administered, it is possible that the steroid had a beneficial effect on pregnancy outcome through the reduction of NK cells. The administration of low-dose aspirin with prednisolone may have reduced uterine vascular resistance by decreasing the local thromboxane A2/ prostacyclin ratio, improving uterine blood perfusion and the implantation rate ${ }^{(\mathbf{1 9})}$.

Also, Gomaa et al. (20) confirmed that the addition of prednisolone to heparin and low dose aspirin might be beneficial in patients with unexplained recurrent miscarriage, and this effect might be due to a suppressive effect of steroids on the peripheral CD16 NK cells concentration.as his result was found that in the prednisolone group, $70.3 \%$ of women had successful outcome (defined as an ongoing pregnancy beyond 20 weeks gestation), while $29.7 \%$ miscarried before this gestation. On the contrary, among women in the Aspirin only group, 9.2\% had successful outcome while $90.8 \%$ miscarried before 20 weeks, which was statistically significant. On the other hand, we found that there were no significant paired differences between initial serum levels of the NK cells markers CD16 and CD56 and their levels at 20 weeks gestation in both groups.

This may explained by Thum et al. (21) who mentioned that the results of this study show that prednisolone is able to suppress the cytolytic activity of the NK cell.

Women who were treated with prednisolone (PSL) plus low dose aspirin (LDA) had a 32.2\% higher live birth rate than the control group with a significant difference between the two groups; the results were in accordance with previously reported data by Etievant et al. ${ }^{(22)}$. The combination of $20 \mathrm{mg} /$ day of prednisone with aspirin and progesterone allowed $85 \%$ of live births in comparison to $48 \%$ with placebo $(\mathrm{P}<0.05)$. Fawzy et $\boldsymbol{a l} .{ }^{(23)}$ as they conducted a prospective, randomized, single-blinded, controlled trial was conducted at a tertiary referral obstetric hospital. The participants were 170 women with a diagnosis of IRM. Women were recruited after full investigative screening. Women with $>$ or $=3$ fetal losses and after exclusion of all known causes of recurrent miscarriage were randomly allocated to receive either enoxaparin alone, combination treatment consisting of prednisone, aspirin, and progesterone or Aspirin only. That resulted of ten patients were dropped out after random assignment. Eighty-one percent of the enoxaparin (46/57) group and $85 \%$ of the combination-treated group (45/53) were delivered of live infants compared to 48\% (24/50) of the Aspirin only $(\mathrm{P}<0.05)$.

Women who were treated with combination therapy had a $4.2 \%$ higher live birth rate than enoxaparin group. This difference was not significant.
Miscarriage rates were significantly lower in the treated groups compared with Aspirin only $(\mathrm{P}<0.05)$. There were no significant differences in late obstetric complications or neonatal mortality between groups.

Also in study of Tempfer et al. ${ }^{(24)}$ eighty of 210 eligible women consented to participate and were treated with prednisone $(20 \mathrm{mg} / \mathrm{d})$ and progesterone $(20 \mathrm{mg} / \mathrm{d})$ for the first 12 weeks of gestation, aspirin $(100 \mathrm{mg} / \mathrm{d})$ for 38 weeks of gestation, and folate $(5 \mathrm{mg}$ every second day) throughout their pregnancies. Fifty of 80 women became pregnant; they were compared with 52 women with IRM (matched for age and number of miscarriages), who became pregnant without treatment during the same observation period. Their study resulted: The overall live birth rates of the treatment and control groups were $77 \%$ (40 of 52) and $35 \%$ (18 of 52) (P 0.04). The rates of first and second trimester miscarriage among the treatment and control groups were $19 \%$ ( 10 of 52 ) and 0 ( 0 of 52 ), and $63 \%$ (33 of 52) and 2\% (1 of 52), respectively (P 0.09 and $\mathrm{P} 1.0$, respectively). The median gestational age at birth and median birth weight did not differ between the groups. They observed two and three cases of premature birth among the treatment and control groups, respectively (P0.3) and no cases of intrauterine growth restriction and Cushing's disease. Of 80 women who started treatment, one woman had an ectopic pregnancy and one woman terminated her pregnancy due to fetal chromosome aberration (trisomy 18). Three women stopped treatment due to nausea, depression, and tachycardia.

In our study, as regarding the occurrence of complications in both groups, there was no statistically significant difference between the two groups as regards bleeding in early pregnancy, pregnancy induced HTN, pre eclamptic toxemia, gestational DM, preterm labour, intrauterine fetal death, intrauterine growth retardation, thrombocytopenia, epistaxis, bleeding per gum, hematuria, DVT, GIT problem, Abruptio placentae $(\mathrm{P}>0.05)$. There was a significant difference between the two groups as regards the development of bruising $(\mathrm{P}<0.05)$.

Which match agreement of Ahmed et al. study which recorded, the outcome regarding completion of first trimester was not related to age, BMI or number of previous abortions in both the study groups. Complications of the use of aspirin calheparin occurred in $60 \%$ of the patients. The most common complication was bruising at injection site occurring in $60 \%$ of the patients followed by bleeding gums $(14.4 \%)$, gastrointestinal troubles $(12.2 \%)$, epistaxis $(10 \%)$ and transient thrombocytopenia in only $2.22 \%$ of the patients. thus we preferred predinisolone association with low dose aspirin in treatment of unexplained recurrent miscarriage due to its low side effect than heparin as Cecilia documented that, Corticosteroids are known to be associated with 
significant side effects, especially at a high dose; these include preterm delivery, preeclampsia, gestational diabetes, and hypertension. Despite this, it was demonstrated that women taking low doses of prednisone until 14 weeks of gestation plus standard therapy can experience favorable pregnancy outcome, with a higher live birth rate ${ }^{(25)}$.

Explaining by other studies demonstrating adverse effects of prednisolone have used doses up to $60 \mathrm{mg}$. Prednisolone is metabolized by the placenta to a relatively inactive metabolite, only $10 \%$ of which crosses into the fetal circulation at doses $<20 \mathrm{mg}$, and therefore, it might be anticipated that low doses may have fewer side effects ${ }^{(\mathbf{1 9})}$.

On the other hand, Xiao et al. ${ }^{(26)}$ said that Longterm usage of prednisone during pregnancy may provoke obstetric complications.

Steroids are widely used during pregnancy in patients with various inflammatory or auto-immune diseases. Among possible adverse effects, high amounts of steroids could result in arterial hypertension, diabetes, prematurity, and low birth weight, but pregnancy adverse effects are uncommon with low prednisone amounts $(<10 \mathrm{mg} /$ day $)$. Several studies assessed the risk of fetal malformation in women taking steroids in first trimester and mainly showed no increased risk.

The only controversial data are on concern the risk of oral cleft. Several retrospective and prospective case- controls studies showed no increase of the risk of oral cleft in women exposed to steroids ${ }^{(27)}$.

However, a randomized controlled trial that compared outcomes after treatment with aspirin plus prednisolone $(40 \mathrm{mg}$ ) or a prophylactic dose of heparin demonstrated no difference in live birth rate but an increased frequency of preterm delivery because of premature rupture of membranes or preeclampsia in the group treated with prednisolone. Another randomized controlled trial in women with 2 or more first-trimester losses found no benefit in rates of fetal loss but increased preterm delivery in women treated with prednisolone (20 mg) plus aspirin compared with aspirin alone. Another report suggested that fetal losses were actually higher in women treated with prednisolone $(10-60 \mathrm{mg})^{(\mathbf{1 9})}$.

These results are in agreement with Cowchock et al. ${ }^{(28)}$ who reported low incidence of preeclampsia and DVT in the treated patients with steroids plus low dose aspirin.

The data of our study indicate that combination treatment of low dose aspirin and prednisone might be an effective, simple and cheap treatment with least side effects for women with idiopathic recurrent miscarriage.

\section{CONCLUSION}

Our data indicate that a combination treatment consisting of prednislone and low dose aspirin, might be an effective treatment for women with idiopathic pregnancy loss. The data presented constitute sufficient evidence, and prospective-randomized trials are encouraged to establish this treatment scheme.

\section{REFERENCES}

1. Gharesi-Fard B, Ghadri JZ and Kamali-Sarvestani E (2014): Alteration in the Expression of Proteins in Unexplained Recurrent Pregnancy Loss Compared with in the Normal Placenta. J Reprod Dev., 60(4): 261-267.

2. Shakarami F, Akbari MT and Karizi SZ (2015): Association of plasminogen activator inhibitor-1 and angiotensin converting enzyme polymo- rphisms with recurrent pregnancy loss in Iranian women. Iran J Reprod Med., 13(10): 627-632.

3. Kashif S, Kashif MA and Saeed A (2015): The association of factor $\mathrm{V}$ leiden mutation with recurrent pregnancy loss. JPMA. The Journal of the Pakistan Medical Association, 65(11):1169-1172.

4. Clifford K, Rai R and Regan L (1997): Future pregnancy outcome in unexplained recurrent first trimester miscarriage. Hum Reprod., 12:387-9.

5. Nybo Andersen AM, Wohlfahrt J, Christens $P$ et al. (2000): Maternal age and fetal loss: population based register linkage study. BMJ., 320:1708-12.

6. Sugiura-Ogasawara M, Ozaki Y and Katano K (2012): Abnormal embryonic karyotype is the most frequent cause of recurrent miscarriage. Hum Reprod., 27:2297-303.

7. Li TC, Markis M, Tomsu M et al. (2002): Recurrent miscarriage, aetiology management and prognosis. Hum Reprod Update, 8: $463-481$.

8. Quenby S, Kalumbi $C$ and Bates $M$ (2005): Prednisolone reduces preconceptual endometrial natural killer cells in women with recurrent miscarriage. Fertil Steril., 84(4):980-4.

9. Tan EM, Cohen AS and Fries JF (1982): The 1982 revised criteria for the classification of systemic lupus erythematosus. Arthritis Rheum., 25:1271-7.

10. Askie LM, Duley L, Henderson-Smart DJ et al. (2007): Antiplatelet agents for prevention of pre- eclampsia: a metaanalysis of individual patient data. Lancet, 369(9575): 1791-8.

11.Tulppala M, Marttunen M, Soderstrom-Anttila V et al. (1997): Low dose aspirin in the prevention of miscarriage in women with unexplained or autoimmune related recurrent miscarriage: effect on prostacyclin and thromboxane A2 production. Human Reproduction, 12(1):191

12. Kaandorp SP, Goddijn M, van der Post JA et al. (2010): Aspirin plus heparin or aspirin alone in women with recurrent miscarriage. New England Journal of Medicine, 362(17):1586-96.

13.De Jong PG, Kaandorp S, Di Nisio M et al. (2014) Aspirin and/or heparin for women with unexplained recurrent miscarriage with or without inherited thrombophilia. doi: 10.1002/ 14651858.CD004734.

14.Zein E, Salah Eldin D and Abd El-Wahab H (2010): Low Dose Aspirin for Improving Pregnancy Rate in 
Patients Undergoing IVF/ICSI. Med J Cairo Univ., 81: 28.

15. Rai R, Backos M, Baxter N et al. (2000): Recurrent miscarriage - an aspirin a day? Hum Reprod., 15 (10): 2220- 2223.

16. Ahmed MM, Aly A, Walaa AM et al. (2016): The role of prophylactic use of low dose aspirin and calheparin in patients with unexplained recurrent abortion. Journal Gynecological Endocrinology, 32(16):970-972.

17.Rai R, Cohen H, Dave M et al. (1997):Randomised controlled trial of aspirin and aspirin plus heparin in pregnant women with recurrent miscarriage associated with phospholipid antibodies (or antiphospholipid antibodies).BMJ., 314:253-7.

18. Tang AW, Alfirevic $\mathrm{Z}$, Turner MA et al. (2013): Prednisolone Trial: Study protocol for a randomised controlled trial of prednisolone for women with idiopathic recurrent miscarriage and raised levels of uterine natural killer (uNK) cells in the endometrium. Trials, 10:102-106.

19.Bramham K, Thomas $M$ and Nelson-Piercy $C$ (2011) First-trimester low-dose prednisolone in refractory antiphospholipid antibody-related pregnancy loss. Blood, 117 (25): 6948-51.

20. Gomaa MF, Abdellatif GE, Mourrad ME et al. (2014): combined oral prednisolone and heparin versus heparin: the effect on peripheral NK cells and clinical outcome in patients with unexplained recurrent miscarriage. Arch Gynecol Obstet., 290(4): 757-762.

21. Thum MY, Bhaskaran S, Abdalla HI et al. (2008): Prednisolone suppresses NK cell cytotoxicity in vitro in women with a history of infertility and elevated NK cell cytotoxicity. Am J Reprod Immunol., 59:259-265.

22. Etievant MF, Cayol V, Xou G et al. (1999): https://www.aphp.fr/contenu/hopital-saint-antoine-1

23. Fawzy M, Shokeir T, El-Tatongy $M$ et al. (2008): Treatment options and pregnancy outcome in women with idiopathic recurrent miscarriage. Archives of Gynecology and Obstetrics, 278(1):33-8.

24. TempferCB, Christine K, Eva-Katrin B et al. (2006): A combination treatment of prednisone, aspirin, folate and progesterone in women with idiopathic recurrent miscarriage: a matched- pair study. Fertility and Sterility, 86: $145-148$.

25.Nalli C and Tincani A (2014): Pregnancy in Antiphospholipid Syndrome: Can we improve Patient Management? IMAJ., 16: 614-615.

26. Xiao J, Xiong J, Zhu F et al. (2012): Effect of prednisone, aspirin, low molecular weight heparin and intravenous immunoglobulin on outcome of pregnancy in women with antiphospholipid syndrome. ExpTher Med., 5(1): 287291.

27. Mekinian A, Cohen J, Alijotas-Reig J et al. (2016): Unexplained recurrent miscarriage and recurrent implantation failure: is there a place for immunomodulation? Am J Reprod Immunol., 76: 8-28

28. Cowchock FS, Reece EA, Balaban D et al. (1992): Repeated fetal losses associated with antiphospholipid antibodies: a collaborative randomized trial comparing prednisone with lowdose heparin treatment. Am J Obstet Gynecol., 166(5): 1318-1323. 